\title{
Unsolved Issues in the Management of High Blood Pressure in Acute Ischemic Stroke
}

\author{
Gordian J. Hubert, Peter Müller-Barna, and Roman L. Haberl \\ Department of Neurology and Neurological Intensive Medicine, Klinikum Harlaching, Städtisches Klinikum München GmbH, \\ Thalkirchner Straße 48, 80337 Munich, Germany \\ Correspondence should be addressed to Gordian J. Hubert; gordian.hubert@klinikum-muenchen.de
}

Received 22 March 2013; Accepted 3 April 2013

Academic Editor: Blas Gil Extremera

Copyright (C) 2013 Gordian J. Hubert et al. This is an open access article distributed under the Creative Commons Attribution License, which permits unrestricted use, distribution, and reproduction in any medium, provided the original work is properly cited.

High blood pressure is common in acute stroke patients. Very high as well as very low blood pressure is associated with poor outcome. Spontaneous fall of blood pressure within the first few days after stroke was associated both with neurological improvement and impairment. Several randomized trials investigated the pharmacological reduction of blood pressure versus control. Most trials showed no significant difference in their primary outcome apart from the INWEST trial which found an increase of poor outcome when giving intravenous nimodipine. Nevertheless, useful information can be extracted from the published data to help guide the clinician's decision. Blood pressure should only be lowered when it is clearly elevated, and early after onset, reduction should be moderate but may be achieved rapidly. No clear recommendations can be given on the substances to use; however, care should be taken with intravenous calcium channel blockers and angiotensin receptor antagonists. Two ongoing randomized trials will help to solve the questions on blood pressure management in acute stroke.

\section{Introduction}

High blood pressure occurs in around $80 \%$ of patients with acute ischemic stroke [1] and usually decreases over the following 7 days [2].

Whether this elevated blood pressure is a physiological and protective reaction or a side effect of a generalised stress reaction that is in fact harmful to the newly damaged brain and whether it should be lowered or not is yet to be answered. This problem is considered as "one of the major unresolved issues in acute stroke management" [3]. American (AHA) and European (ESO) guidelines recommend not to treat elevated blood pressure unless above $220 / 120 \mathrm{mmHg}$ and describe an urgent need for large well-designed trials to address this issue $[4,5]$. Currently there are two large ongoing trials: the "Efficacy of Nitric Oxide in Stroke" trial (ENOS) compares nitric oxide versus placebo and continuing versus stopping previously taken antihypertensive agents in acute stroke [6]. ENCHANTED compares low dose versus normal dose of recombinant tissue-type plasminogen activator
(r-tPA) and intensive blood pressure reduction versus standard reduction in thrombolysed patients [7].

This article focuses on currently available data, the contraries of the results, and potential solutions.

\section{Initial Blood Pressure and Outcome}

Several observational studies looked into the relationship of high initial blood pressure and outcome. A post hoc analysis of the International Stroke Trial found a U-shaped relationship between initial blood pressure and outcome, indicating that systolic blood pressure of around $140-180 \mathrm{mmHg}$ is associated with best outcome [1]. These findings were confirmed in another study showing that very high and very low initial blood pressure is associated with increased death rates [8]. High blood pressure was also independently associated with recurrent ischemic stroke and cerebral edema $[1,9]$.

Patients with very low initial blood pressure had a higher incidence of heart failure and coronary heart disease. This 
TABLE 1: Important randomised controlled trials of intervention versus control. SBP: systolic blood pressure, MAP: mean arterial pressure, AH: antihypertensive agents, p.o.: per os, i.v.: intravenous, n.p.: not published. (The phase II trial ACCESS comparing candesartan versus placebo has not been included, as the following phase III trial SCAST has been).

\begin{tabular}{|c|c|c|c|c|c|c|c|}
\hline Name & $\begin{array}{c}\text { Year of } \\
\text { publication }\end{array}$ & $n$ & $\begin{array}{c}\text { Initial median blood } \\
\text { pressure }(\mathrm{mmHg})\end{array}$ & $\begin{array}{c}\text { Time to treatment } \\
\text { (hours) }\end{array}$ & Substance & $\begin{array}{l}\text { Administra- } \\
\text { tion }\end{array}$ & Stroke subgroup \\
\hline BEST [21] & 1988 & 302 & n.p. & $22-25.3$ & Atenolol, Propanolol & p.o. & $\begin{array}{c}\text { Ischemic }+ \\
\text { hemorrhagic }\end{array}$ \\
\hline INWEST [23] & 1994 & 295 & SBP 159-161 & $10.5-11.5$ & Nimodipine & i.v. & Ischemic \\
\hline Rashid et al. [27] & 2003 & 90 & SPB 151 & 51 & Glyceryl Trinitrate & transdermal & $\begin{array}{l}\text { Ischemic + } \\
\text { hemorrhagic }\end{array}$ \\
\hline IMAGES [25] & 2004 & 2589 & MAP 108 & 7 & Magnesium & i.v. & $\begin{array}{l}\text { Ischemic + } \\
\text { hemorrhagic }\end{array}$ \\
\hline CHHIPS [28] & 2009 & 179 & SBP 181 & $17.4-20.5$ & Labetalol, Lisinopril & $\begin{array}{l}\text { p.o., i.v., } \\
\text { sublingual }\end{array}$ & $\begin{array}{c}\text { Ischemic }+ \\
\text { hemorrhagic }\end{array}$ \\
\hline COSSACS [29] & 2010 & 763 & SBP 150 & 23.5 & Previously taken AH & any & $\begin{array}{c}\text { Ischemic }+ \\
\text { hemorrhagic }\end{array}$ \\
\hline SCAST [30] & 2011 & 2029 & SBP 171 & 17.8 & Candesartan & p.o. & $\begin{array}{c}\text { Ischemic + } \\
\text { hemorrhagic }\end{array}$ \\
\hline
\end{tabular}

might explain part of their worse outcome. The reason for poor outcome after initial high blood pressure seems more complex. High blood pressure after acute ischemic stroke causes brain edema [10], and brain edema decreases cerebral blood flow $[11,12]$, thus aggravating cerebral ischemia. Another mechanism could be that endogenous tPA release is reduced when blood pressure is high due to the damage at the endothelium [13-15].

One critique of those studies is that blood pressure was measured only on admission, usually several hours after stroke onset $[1,8,16,17]$. However, variability and duration of high blood pressure in the first hours after stroke onset may be more relevant for prognosis.

\section{Spontaneous Change in Blood Pressure and Outcome}

Several observational studies looked into the prognosis of spontaneous change in blood pressure during the acute phase with divergent results. The Barcelona Downtown stroke registry found that early decrease of systolic blood pressure by $20-30 \%$ was associated with full recovery (OR 2.9, 95\% CI 1.3-6.3) [16]. A decrease in systolic blood pressure within 12 hours was associated with recanalization of the vessel [18]. In other studies spontaneous decrease of blood pressure within 24 hours was associated with poor outcome [19] and early neurological deterioration [20].

There might be a bias when looking into spontaneous decrease of blood pressure and correlating it to outcome. Rapid spontaneous decrease might reflect less severe stroke [17], recanalization of the vessel [18], or might be due to cardiac insufficiency [8], all of which have an independent effect on outcome. So it might be a sign for a rapidly resolving or rapidly deteriorating process, explaining the divergent results.

\section{Intervention of Elevated Blood Pressure and Outcome}

Several randomised controlled trials addressed the topic of blood pressure management in acute stroke (see Table 1). The trials are heterogeneous regarding time to treatment, degree and speed of effective blood pressure reduction, substances used, and the stroke subgroups included (i.e., ischemic, hemorrhagic strokes, or both).

Beta-blockers given within 48 hours after hemispheric stroke increased mortality (BEST) [21]. The treatment groups, however, were unbalanced with more severely disabled patients in the group receiving beta blockers. Also patients did not have to have elevated blood pressure to be included in the trial. The calcium antagonist nimodipine was investigated in several trials in the 1990s. A metaanalysis of nine trials showed a significant benefit from oral nimodipine versus placebo when given within 12 hours of symptom onset [22]. In contrast, intravenous nimodipine given as $1 \mathrm{mg} / \mathrm{h}$ and $2 \mathrm{mg} / \mathrm{h}$ increased the rate of poor neurological and functional outcome in ischemic stroke patients compared to placebo (INWEST) [23]. A correlation was found between the amount of diastolic blood pressure reduction in the high-dose group and poor functional outcome [24].

Intravenous magnesium administered within 12 hours lowered systolic blood pressure by $4 \mathrm{mmHg}$ and showed a trend towards improved outcome in all stroke patients (odds ratio: $0.95,95 \%$ CI $0.80-1.13, P=0.59$ ). For the subgroup of patients with elevated blood pressure (mean arterial pressure $>108 \mathrm{mmHg}$ ), improvement was significant (odds ratio of 0.78, 95\% CI 0.61-0.99) [25].

Smaller trials with glyceryl trinitrate showed no significant difference in functional outcome $[26,27]$ but were also not powered to do so.

The early administration of labetalol and lisinopril lead to a significant reduction in blood pressure as compared to the placebo group (mean systolic difference $10 \mathrm{mmHg}$, 
95\% CI 3-17, $P=0.004$ ) (CHHIPS). Death and dependency at 3 months did not differ, but 3 months mortality was halved in the treatment group to $9,7 \%$ from $20,3 \%$ (HR $0.4,95 \%$ CI $0.2-1.0, P=0.05)$. The intervention was safe regarding early neurological outcome and serious adverse events [28].

The COSSACS trial looked into the question whether previously taken antihypertensive agents should be stopped or continued in patients with acute stroke. The trial included patients within 48 hours from symptom onset. Continuing the medication reduced blood pressure significantly $(13 / 8 \mathrm{mmHg}$ lower at two weeks). No difference was seen in the primary outcome death or dependency at two weeks, but there was a significant functional improvement in the subgroup of patients with confirmed acute ischemic stroke (relative risk 0.70, 95\% CI 0.51-0.99, $P=0.045$ ) [29].

Another trial (SCAST) compared candesartan to placebo within 30 hours after onset looking at a combined vascular endpoint. Blood pressure reduction was only moderate, and no significant differences in the endpoints were seen. A trend favouring placebo was noticed [30].

A metaregression on actively lowered blood pressure in acute stroke including 9008 patients from randomized trials showed the lowest odds ratio $(0.95,95 \%$ CI $0.11-1.72)$ for death or dependency with a decrease of systolic blood pressure by $14 \mathrm{mmHg}$ [31].

Two Cochrane analyses concluded that there is insufficient evidence to evaluate the effect of blood pressure changes on outcome after acute stroke $[32,33]$.

\section{Discussion}

The management of blood pressure in acute ischemic stroke remains unclear due to divergent results of the studies. The effect of blood pressure management appears to differ in various patient populations. The effect might be dependent on level of initial blood pressure, time to treatment, stroke severity, and history of hypertension, as well as intensity of blood pressure lowering, substances used, and administration form (e.g., i.v. or oral). Some of the possible influences should be looked at in more detail.

5.1. Initial Level of Blood Pressure. It is evident that lowering blood pressure of normotensive patients in acute stroke may lead to hypotensive events, thus deteriorating outcome. Therefore, blood pressure lowering should only be considered when it is elevated. The negative effect of the BEST trial might partly be explained by inclusion of normotensive patients with systolic blood pressure $>100 \mathrm{mmHg}$ [21]. In a subgroup of IMAGES only those patients with higher blood pressure levels had a benefit (mean arterial pressure $>108 \mathrm{mmHg}$ ) [25]. This matches with CHHIPS and COSSACS in which mean systolic level was high $(181 \mathrm{mmHg}$ and $150 \mathrm{mmHg}$ ), and decreased mortality and improved functional outcome in the subgroup with ischemic stroke were seen, respectively $[28,29]$. Observational data showed that low initial blood pressure increased poor outcome $[1,8]$. However, there are also trials in which treating elevated blood pressure did harm (INWEST) or showed a trend favoring placebo (SCAST) $[23,30]$.
5.2. When to Start Treatment. The earlier acute stroke treatment is initiated, the better the outcome [34]. This seems to apply to blood pressure management too. Significant benefit from oral nimodipine versus placebo was seen when given within 12 hours after onset, no benefit between 12 and 24 hours, and worse outcome when initiated after 24 hours [22]. In IMAGES, magnesium was given early at a mean of about 7 hours after onset (max. 12 hours) and showed a benefit in those with elevated blood pressure [25]. In SCAST, treatment was started after about 17 hours and did no benefit. A small subgroup treated within 6 hours, however, did better [30]. In fact, the later treatment was started, the more did Candesartan seem to harm the patient regarding the composite vascular endpoint [30]. Other trials showed the opposite. Nimodipine was started early (11 hours after onset) and had a negative effect [23]. CHHIPS and COSSACS started treatment late and were neutral, even with some positive secondary endpoints $[28,29]$. Although the start of treatment is known for most of the trials, the lag until achieving effective blood pressure reduction is not. This may influence the results.

5.3. How Fast and How Much to Lower Blood Pressure. It is agreed that a rapid and large decrease in blood pressure is dangerous for acute stroke patients. This opinion is largely based on the data from INWEST and some observational data $[19,20,23]$. High-dose (but not low-dose) intravenous nimodipine was associated with death and dependency when diastolic blood pressure was lowered by $>20 \%$ within the first two days [24]. A secondary analysis of SCAST showed that a large systolic decrease of $>28 \mathrm{mmHg}$ was significantly associated with poor outcome [35]. Moderate reduction of blood pressure seems to be safe and even protective. Magnesium reduced blood pressure within 24 hours by $4 / 3 \mathrm{mmHg}$ and showed a benefit for those with higher blood pressure. In CHHIPS the systolic blood pressure difference was $10 \mathrm{mmHg}$ within the first 24 hours, and mortality was halved after 3 months. A decrease of even $16 \mathrm{mmHg}$ was achieved within 4 hours with labetalol compared to placebo, and this was found to be safe [28]. So the rapid reduction does not seem to be dangerous, as long as reduction is moderate.

5.4. Which Substance to Use. No clear answer can be given to this question as yet. Some trials included various classes $[28,29]$, and others looked into the effect of a single one. The calcium channel blocker nimodipine had a positive effect when given orally within 12 hours, but a negative effect when given intravenously. The angiotensin-convertingenzyme inhibitor lisinopril had a positive effect on 3 months mortality [28], and the angiotensin receptor antagonist candesartan possibly has an injurious effect on the brain [30]. Nitric oxide donors found stable cerebral blood flow albeit reducing blood pressure effectively $[27,36]$, and the mixed alpha/beta-receptor antagonist labetalol showed reduction of 3-month mortality [28].

5.5. Safety. Several data showed that lowering blood pressure in acute ischemic stroke is safe in terms of early neurological 
deterioration and functional outcome [26-29], even in the presence of carotid artery stenosis [37] and that it does not decrease perfusion in the region of the infarct [27, 36, 38-40].

\section{Conclusion}

Trials looking at the effect of blood pressure reduction in the acute phase of stroke are heterogeneous in design, classes of antihypertensive agents, achieved blood pressure reduction, and influence on outcome. Although the guideline recommendation is not to lower blood pressure in the range up to $220 / 120 \mathrm{mmHg}$, there might be some neuroprotective effect of very early (first 7-10 hours after stroke) and rather moderate (10-20 $\mathrm{mmHg}$ ) blood pressure lowering. Substance classes may differ in that respect, but care should be taken with intravenous calcium channel blockers and angiotensin receptor antagonists. Adequately powered, randomized trials, however, are urgently warranted to substantiate those speculations.

\section{References}

[1] J. Leonardi-Bee, P. M. W. Bath, S. J. Phillips, and P. A. G. Sandercock, "Blood pressure and clinical outcomes in the International Stroke Trial," Stroke, vol. 33, no. 5, pp. 1315-1320, 2002.

[2] M. Britton, A. Carlsson, and U. De Faire, "Blood pressure course in patients with acute stroke and matched controls," Stroke, vol. 17, no. 5, pp. 861-864, 1986.

[3] U. Fischer and P. M. Rothwell, "Blood pressure management in acute stroke," Stroke, vol. 42, no. 10, pp. 2995-2998, 2011.

[4] E. C. Jauch, J. L. Saver, H. P. Adams Jr. et al., "Guidelines for the early management of patients with acute ischemic stroke: a guideline for healthcare professionals from the American Heart Association/American Stroke Association," Stroke, vol. 44, no. 3, pp. 870-947, 2013.

[5] European Stroke Organisation (ESO) Executive Committee and ESO Writing Committee, "Guidelines for management of ischaemic stroke and transient ischaemic attack 2008," Cerebrovascular Diseases, vol. 25, no. 5, pp. 457-507, 2008.

[6] The ENOS Trial Investigators, "Glyceryl trinitrate versus control, and continuing versus stopping temporarily prior antihypertensive therapy, in acute stroke: rationale and design of the Efficacy of Nitric Oxide in Stroke (ENOS) trial (ISRCTN99414122)," International Journal of Stroke, vol. 1, no. 4, pp. 245-249, 2006.

[7] "ENCHANTED," http://clinicaltrials.gov/ct2/show/NCT01422616.

[8] K. N. Vemmos, G. Tsivgoulis, K. Spengos et al., "U-shaped relationship between mortality and admission blood pressure in patients with acute stroke," Journal of Internal Medicine, vol. 255, no. 2, pp. 257-265, 2004.

[9] M. Willmot, J. Leonardi-Bee, and P. M. W. Bath, "High blood pressure in acute stroke and subsequent outcome: a systematic review," Hypertension, vol. 43, no. 1, pp. 18-24, 2004.

[10] Q. J. Durward, R. F. Del Maestro, A. L. Amacher, and J. K. Farrar, "The influence of systemic arterial pressure and intracranial pressure on the development of cerebral vasogenic edema," Journal of Neurosurgery, vol. 59, no. 5, pp. 803-809, 1983.

[11] S. A. Mayer, C. E. Thomas, and B. E. Diamond, "Asymmetry of intracranial hemodynamics as an indicator of mass effect in acute intracerebral hemorrhage: a transcranial Doppler study," Stroke, vol. 27, no. 10, pp. 1788-1792, 1996.

[12] J. Treib, S. C. Becker, M. T. Grauer, and A. Haass, "Transcranial Doppler monitoring of intracranial pressure therapy with mannitol, sorbitol and glycerol in patients with acute stroke," European Neurology, vol. 40, no. 4, pp. 212-219, 1998.

[13] T. Hrafnkelsdóttir, U. Wall, C. Jern, and S. Jern, "Impaired capacity for endogenous fibrinolysis in essential hypertension," The Lancet, vol. 352, no. 9140, pp. 1597-1598, 1998.

[14] T. Hrafnkelsdóttir, T. Gudnason, U. Wall, C. Jern, and S. Jern, "Regulation of local availability of active tissue-type plasminogen activator in vivo in man," Journal of Thrombosis and Haemostasis, vol. 2, no. 11, pp. 1960-1968, 2004.

[15] L. S. Sjögren, R. Doroudi, L. M. Gan, L. Jungersten, T. Hrafnkelsdóttir, and S. Jern, "Elevated intraluminal pressure inhibits vascular tissue plasminogen activator secretion and downregulates its gene expression," Hypertension, vol. 35, no. 4, pp. 1002-1008, 2000.

[16] A. Chamorro, N. Vila, C. Ascaso, E. Elices, W. Schonewille, and R. Blanc, "Blood pressure and functional recovery in acute ischemic stroke," Stroke, vol. 29, no. 9, pp. 1850-1853, 1998.

[17] H. Christensen, G. Boysen, H. H. Johannesen, E. Christensen, and K. Bendtzen, "Deteriorating ischaemic stroke: cytokines, soluble cytokine receptors, ferritin, systemic blood pressure, body temperature, blood glucose, diabetes, stroke severity, and $\mathrm{CT}$ infarction-volume as predictors of deteriorating ischaemic stroke," Journal of the Neurological Sciences, vol. 201, no. 1-2, pp. $1-7,2002$.

[18] H. P. Mattle, L. Kappeler, M. Arnold et al., "Blood pressure and vessel recanalization in the first hours after ischemic stroke," Stroke, vol. 36, no. 2, pp. 264-268, 2005.

[19] J. Oliveira-Filho, S. C. S. Silva, C. C. Trabuco, B. B. Pedreira, E. U. Sousa, and A. Bacellar, "Detrimental effect of blood pressure reduction in the first 24 hours of acute stroke onset," Neurology, vol. 61, no. 8, pp. 1047-1051, 2003.

[20] J. Castillo, R. Leira, M. M. García, J. Serena, M. Blanco, and A. Dávalos, "Blood pressure decrease during the acute phase of ischemic stroke is associated with brain injury and poor stroke outcome," Stroke, vol. 35, no. 2, pp. 520-527, 2004.

[21] D. H. Barer, J. M. Cruickshank, S. B. Ebrahim, and J. R. Mitchell, "Low dose beta blockade in acute stroke ("BEST" trial): an evaluation," British Medical Journal, vol. 296, no. 6624, pp. 737741, 1988.

[22] J. P. Mohr, J. M. Orgogozo, M. J. G. Harrison et al., "Metaanalysis of oral nimodipine trials in acute ischemic stroke," Cerebrovascular Diseases, vol. 4, no. 3, pp. 197-203, 1994.

[23] N. G. Wahlgren, D. G. MacMahon, J. de Keyser, B. Indredavik, and T. Ryman, "Intravenous nimodipine West European stroke trial (INWEST) of nimodipine in the treatment of acute ischaemic stroke," Cerebrovascular Diseases, vol. 4, no. 3, pp. 204-210, 1994.

[24] N. Ahmed, P. Näsman, and N. G. Wahlgren, "Effect of intravenous nimodipine on blood pressure and outcome after acute stroke," Stroke, vol. 31, no. 6, pp. 1250-1255, 2000.

[25] IMAGES Investigators, "Magnesium for acute stroke: randomised controlled trial," The Lancet, vol. 363, pp. 439-445, 2004.

[26] P. M. W. Bath, R. Pathansali, R. Iddenden, and F. J. Bath, "The effect of transdermal glyceryl trinitrate, a nitric oxide donor, on blood pressure and platelet function in acute stroke," Cerebrovascular Diseases, vol. 11, no. 3, pp. 265-272, 2001. 
[27] P. Rashid, C. Weaver, J. Leonardi-Bee, F. Bath, S. Fletcher, and P. Bath, "The effects of transdermal glyceryl trinitrate, a nitric oxide donor, on blood pressure, cerebral and cardiac hemodynamics, and plasma nitric oxide levels in acute stroke," Journal of Stroke and Cerebrovascular Diseases, vol. 12, no. 3, pp. 143-151, 2003.

[28] J. F. Potter, T. G. Robinson, G. A. Ford et al., "Controlling hypertension and hypotension immediately post-stroke (CHHIPS): a randomised, placebo-controlled, double-blind pilot trial," The Lancet Neurology, vol. 8, no. 1, pp. 48-56, 2009.

[29] T. G. Robinson, J. F. Potter, G. A. Ford et al., "Effects of antihypertensive treatment after acute stroke in the continue or stop post-stroke antihypertensives collaborative study (COSSACS): a prospective, randomised, open, blinded-endpoint trial," The Lancet Neurology, vol. 9, no. 8, pp. 767-775, 2010.

[30] E. C. Sandset, P. M. W. Bath, G. Boysen et al., "The angiotensinreceptor blocker candesartan for treatment of acute stroke (SCAST): a randomised, placebo-controlled, double-blind trial," The Lancet, vol. 377, no. 9767, pp. 741-750, 2011.

[31] C. M. Geeganage and P. M. W. Bath, "Relationship between therapeutic changes in blood pressure and outcomes in acute stroke: a metaregression," Hypertension, vol. 54, no. 4, pp. 775781, 2009.

[32] C. Geeganage and P. M. Bath, "Interventions for deliberately altering blood pressure in acute stroke," Cochrane Database of Systematic Reviews, no. 4, p. CD000039, 2008.

[33] C. Geeganage and P. M. Bath, "Vasoactive drugs for acute stroke," Cochrane Database of Systematic Reviews, vol. 7, p. CD002839, 2010.

[34] K. R. Lees, E. Bluhmki, R. von Kummer et al., "Time to treatment with intravenous alteplase and outcome in stroke: an updated pooled analysis of ECASS, ATLANTIS, NINDS, and EPITHET trials," The Lancet, vol. 375, no. 9727, pp. 1695-1703, 2010.

[35] E. C. Sandset, G. D. Murray, P. M. W. Bath, S. V. Kjeldsen, E. Berge, and On behalf of the Scandinavian Candesartan Acute Stroke Trial (SCAST) Study Group, "Relation between change in blood pressure in acute stroke and risk of early adverse events and poor outcome," Stroke, vol. 43, no. 8, pp. 2108-2114, 2012.

[36] M. Willmot, A. Ghadami, B. Whysall, W. Clarke, J. Wardlaw, and P. M. W. Bath, "Transdermal glyceryl trinitrate lowers blood pressure and maintains cerebral blood flow in recent stroke," Hypertension, vol. 47, no. 6, pp. 1209-1215, 2006.

[37] G. M. Sare, L. J. Gray, J. Wardlaw, C. Chen, and P. M. W. Bath, "Is lowering blood pressure hazardous in patients with significant ipsilateral carotid stenosis and acute ischaemic stroke? Interim assessment in the 'Efficacy of Nitric Oxide in Stroke' Trial," Blood Pressure Monitoring, vol. 14, no. 1, pp. 20-25, 2009.

[38] W. J. Powers, T. O. Videen, M. N. Diringer, V. Aiyagari, and A. R. Zazulia, "Autoregulation after ischaemic stroke," Journal of Hypertension, vol. 27, no. 11, pp. 2218-2222, 2009.

[39] F. S. Nazir, J. R. Overell, A. Bolster, T. E. Hilditch, and K. R. Lees, "Effect of perindopril on cerebral and renal perfusion on normotensives in mild early ischaemic stroke: a randomized controlled trial," Cerebrovascular Diseases, vol. 19, no. 2, pp. 7783, 2005.

[40] G. M. Sare, L. J. Gray, and P. M. W. Bath, "Effect of antihypertensive agents on cerebral blood flow and flow velocity in acute ischaemic stroke: systematic review of controlled studies," Journal of Hypertension, vol. 26, no. 6, pp. 1058-1064, 2008. 


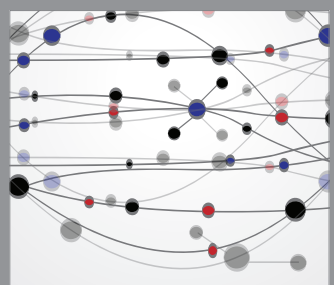

The Scientific World Journal
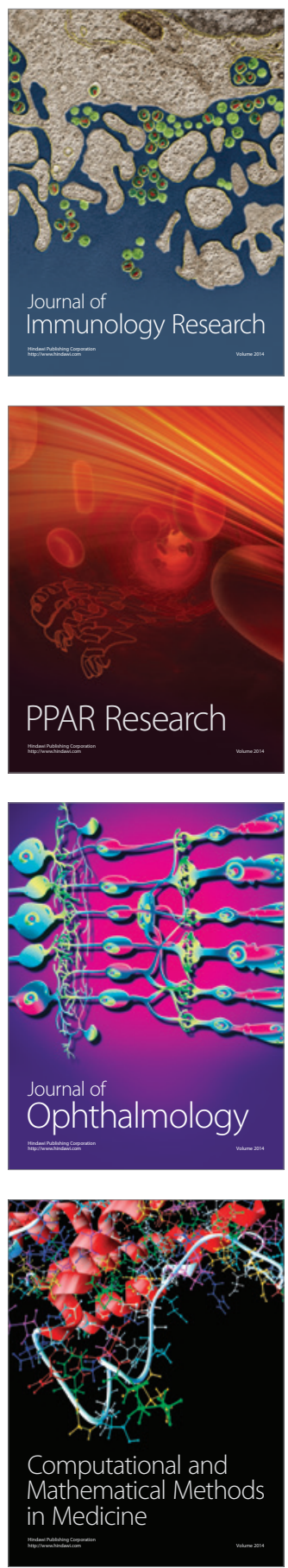

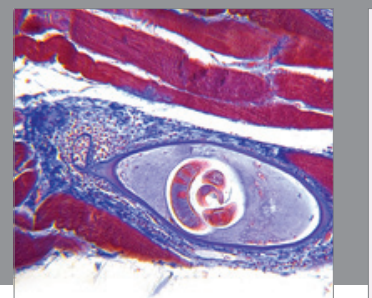

Gastroenterology

Research and Practice
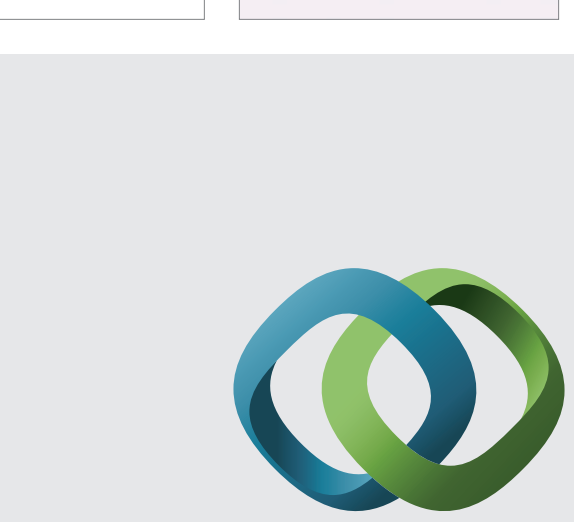

\section{Hindawi}

Submit your manuscripts at

http://www.hindawi.com
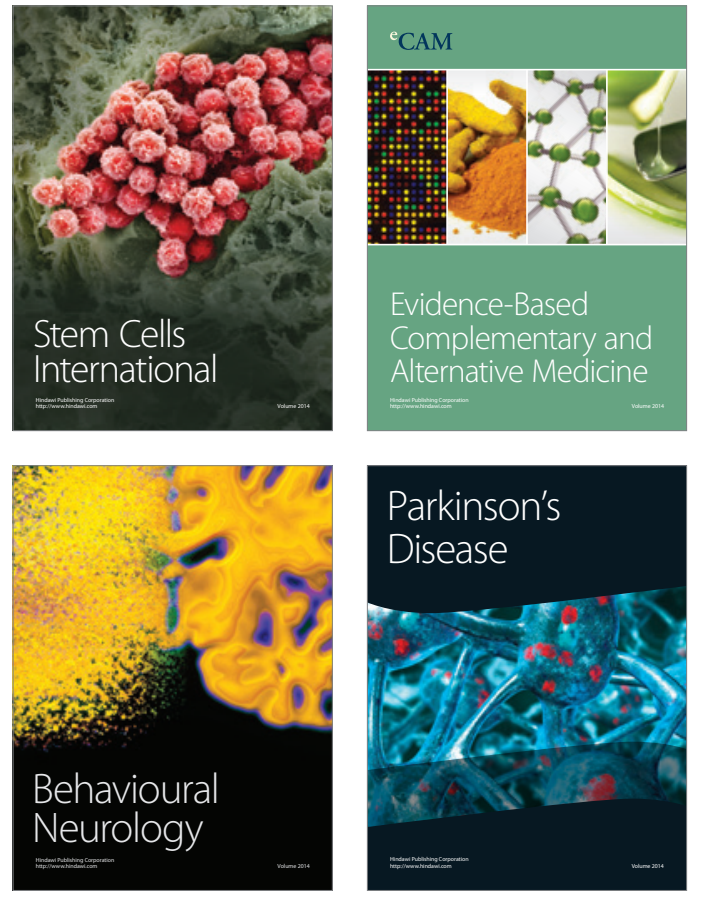
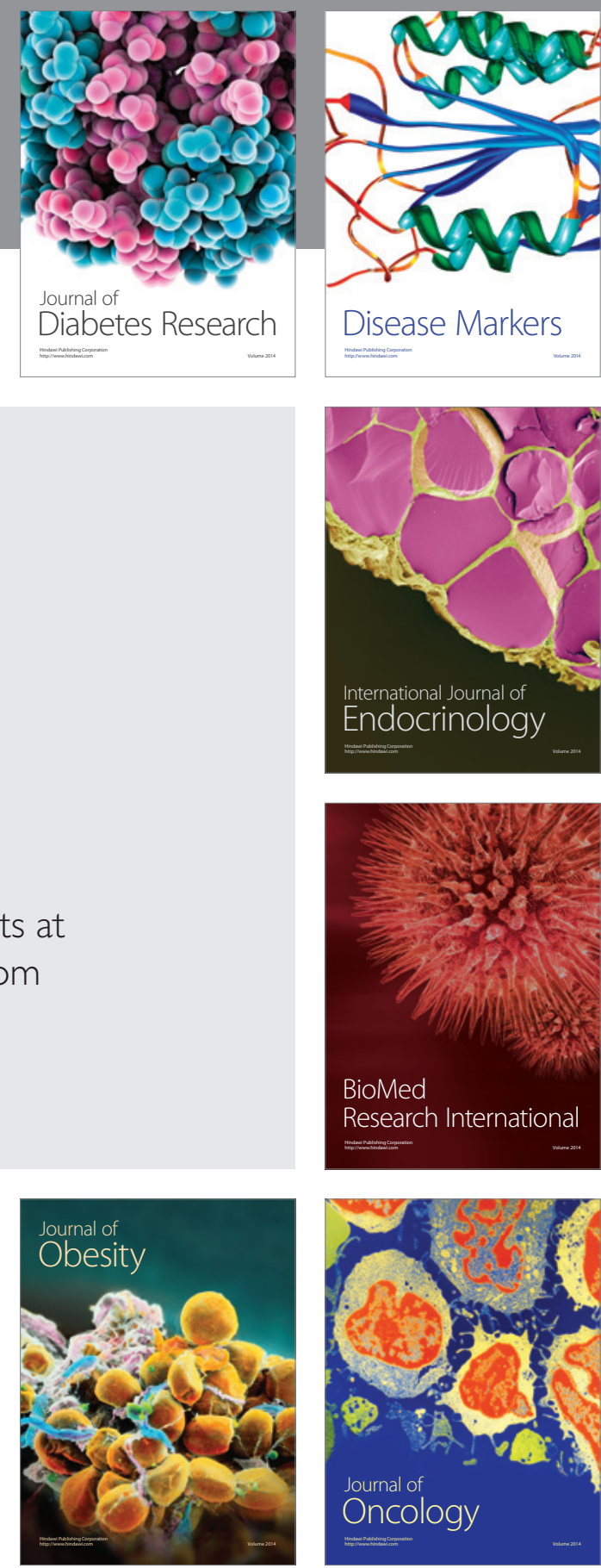

Disease Markers
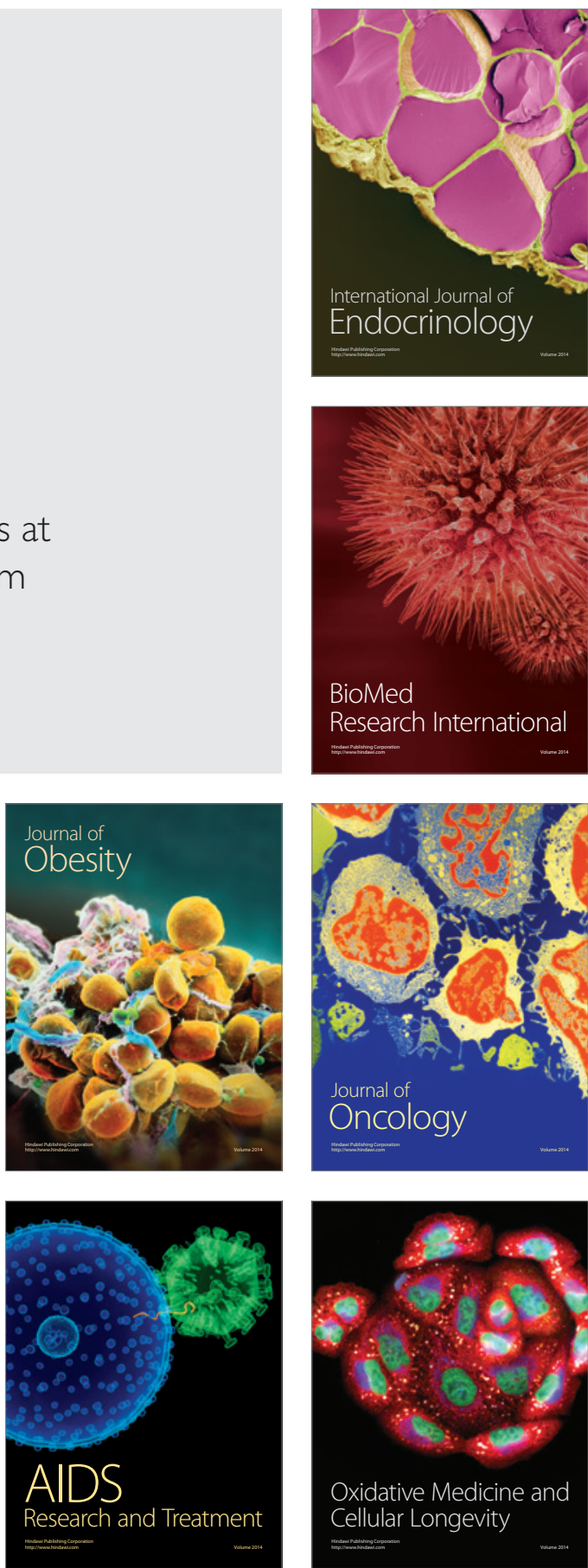